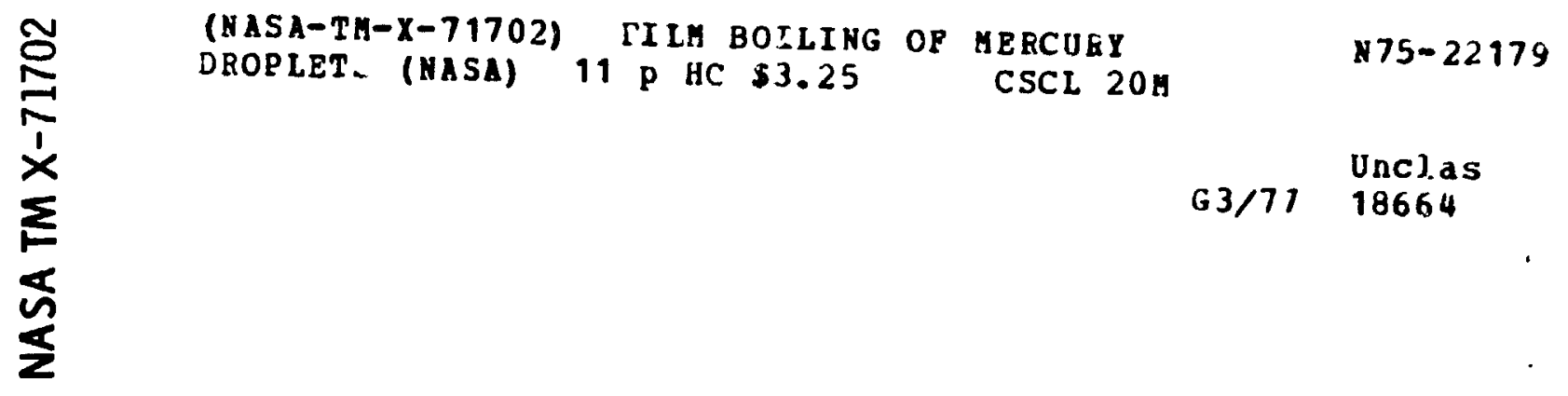

\title{
FILM BOILING OF MERCURY DROPLETS
}

by Kenneth J. Baumeister

Lewis Research Center

Cleveland, Ohio 44135

Glen J. Schoessow

University of Florida

Gainesville, Florida 32601

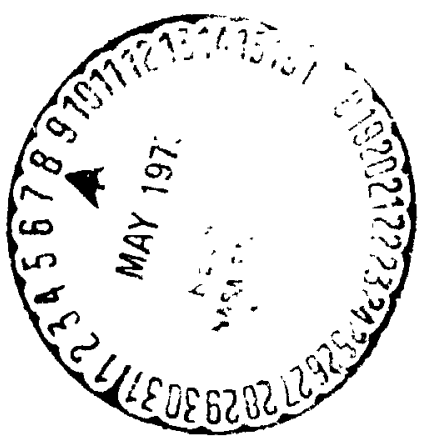

and Charles E. Chmielewski

Florida Light and Power Company

Miami, Florida 33158

TECHNICAL PAPER to be presented at

National Heat Transfer Conference

San Francisco, California, August 11-13, 1975 
FILM BOIL ING OF MERCURY LROFLETS

by Kenneth J. Baumeister*, Glen J. Schoessow** and Charles E. Chmielewski

\section{Abstract}

Vaporization times of mercury droplets in Leicenfrost film boiling on a flat horizontal plate are measured in an air atmosphere. Extreme care was used to prevent large amplitude droplet vibrations and surface wetting; therefore, these data can be compered to film boiling theory. For these data, diffusion from the upper surface of the drop is a dominant mode of mass transfer from the drop. A closed-form analytical film boiling theory is developed to account for the diffusive evaporation. Reasonable agreement between data and theory is seen.

\section{Introduction}

Up to the present time, in the study of film boiling of liquid droplets, most experiments have consldered fluids such as water, hydrocarbons, or cryogens. Refrrences 1 to 6 provide a comprehensive simmary of past work plus a discusston of the phenomenon of oroplet film boiling, often called Leidenfrost boiling. Recent interest in liquidmetal fast-breeder reactors and concern for their safe operation has lead to the need for film boiling deta for liquid metals. In this paper, the authors' report vaporization times of mercury droplets in fllm boiling on a flat horizontal plate in an air atmosphere and correlate the data. The heat transfer coefficient, plate temperatures, etc, are also reported.

Poppendiek, et al. tave reported some film bolling data of mercury sroplets. 7,8 They reported that large amplitude droulet vibrations and interantion of the droplet with the surface occurred during the vaporization process. The authors report the raporizstion time of only a single size droplet and infort nately give only an average droplet radius ruthe": than an exact volume measurement.

eliminat s the problems described by Poppendlek, et. $\mathrm{si}$. only very small mercury droplet volumes $(0.37 \mathrm{~cm}$ in diam. or less) were used herein to obtain etable film bolling with a minimum of droplet vitration and surface wetting.

In an air atmosphere in the volume range considered, wiffision fram the upper surface of the drop is a dcminant mode of mass transfer as shown by an evaluation of the dimensionless groups develoyed ierein ano shown by some experimental date from $h: f$. $i$. The proviously-developed closed form theorles fin the heat transfer coefficient and vaporiz' ile times elther neglected or considered diffusion from the upper surface of the drop as a small part of the mass transfer process. As a result, these theorles, such as developed in Refs. 1 or 10, can not be used to correlate the data. The numerical scheme presented in Ref. 2 could be applied. However, since a closed-form analytical theory is convenient, a closed-form solution was sought and is presented herein for the heat tra:sfer coefficient and vaporization time of droplets in diffusion-dominated film boiling.

The analysis is limited to two-component systems invuiving a pure single-component liquid with small solubilities for the gas and a singlecomponent as of high purity (with the exception of air for which measured values of the diffision ccefficient exist).

\section{Experimental Apparatus and Procedure}

The experimental equipment consisted basicully of a heated flat surface insulated on 1ts sides. The initial droplet vaporization experimerts on the hot surface were conducted ir. a cylindrical tank $60 \mathrm{~cm}$ in diameter and $60 \mathrm{~cm}$ long with a helium atmosphere. This apparatus was the same one used in Ref. 8 to measure the effects of the environmental diffusivity on the vaporization times of the drops. The first data point taken for a drop in a dry environment was always repeated at the enc of a deta set to check for repeatability.

Although the remote handling was inherently a safer way to conduct the vaporization experiments with mercury which is toxic, remote handing made close observation and accurate volume control difficult. Instead of using the closed chamber, the flat heated plate was operated in an open air atmosphere inside a hood. In this way, the mercury droplet could be placed by hand on the surface in more gentle manner and thereby eliminate much of the droplet vibration problems discussed in Ref. 7 and seen in our earlier experiments.

The oxidatios of the mercury drop did not appear to be much of a problem based on the volume of the residue left at the end of the evaporation. In addition, check was made against data in the helIum atmosphere (approximately the same theoretical diffusivity) and found to be in agreement. Also, as w11l be shown later, in oither air or an inert at. mosphere, the dominant mechanism of mass transfer is diffusion. Alr is the only gas for which a messured value of the diffusion constant for mercury is given. 12

\footnotetext{
*NASA-Lewis Research Center, Cleveland, Ohio 44135

* University ce Florida, Department of Nuclear Englnearing, Gainesville, Florida 32601

t Florida Lighi and Power Company, Miami, Florlda 33158
} 
expression for the hest transfer coefficient is developed by analyzing the model shown in F1g. 3 . Heat transfer to the drop occurs by conduction across the small vapor gap and by radiation from plate to the drop. Mass is lost by diffusive evaporation from the upper surface of the sphere and by flim bolling off the bottom of the drop. The complete andysis for $h$ is presented in Appendix $A$. The relationship of $A_{B}$ to droplet volume is given in Appendix $B$.

First, eq. (2) will be non-dimensionalized usIng the same definitions a.s in Ref. 10. Let

$$
\begin{aligned}
& t^{*}=\frac{t}{\lambda_{\rho_{L}}\left[\frac{\mu_{L}{ }^{5}}{k^{3} \lambda^{*} g\left(\rho_{L}-\rho_{V}\right) \rho_{v} \Delta r^{3}}\right]^{I / 4}} \\
& V^{*}=\frac{V}{L^{3}} \\
& A_{B}^{*}=\frac{A_{B}}{L^{2}} \\
& L=\left[\frac{\sigma_{c}}{\left(\rho_{L}-\rho_{v}\right) g}\right]^{1 / 2} \\
& h^{*}=\frac{h}{\left[\frac{k^{3} \lambda^{*}\left(q_{L}-o_{v}\right) o_{v} 8}{\Delta r \mu L}\right]^{1 / 4}}
\end{aligned}
$$

Eq. (2) can now be written as

$$
-d V^{*}=h_{T}^{*} A_{B}^{*} d t^{*}
$$

Integrating oq. (8) gives:

$$
t^{*}=\int_{v^{*}}^{0} \frac{-d v^{*}}{n_{T}^{*} A_{B}^{*}}
$$

Substituting the expression for $h_{T}, \bullet q$. (ALS) and $A_{3}^{*},\left(\pi x^{2}\right.$, eq. (B2)), into eq. (9) and performing the intigration fives

$$
t^{*}=\frac{6.02}{N^{*}} v^{* 0.664}
$$

whare

$$
N^{*}=\frac{\left(\frac{30.7 \lambda D_{A B^{N P_{B}}}}{\Delta T R T_{B}}\right)}{\left[\frac{\mathrm{k}^{3} \lambda\left(D_{L}-Q_{V}\right) Q_{V} 8}{\Delta T \mu L}\right]^{1 / 4}}
$$

Equation (10) will be compared to the experimentel data in a later section.

\section{Heat Transfer Coefficient}

The varlous heat travsfer mechandsms cambline to give a total heat transfer coefficient that can be found by rearranging eq. (z) into the form

$$
n_{T}=\frac{-\lambda p_{L} \frac{d V}{d t}}{A_{B} \Delta T}
$$

The $\mathrm{dV} / \mathrm{dt}$ term was found at selected volumes by measuring the slope of the vaporization curves in F1g. 1. The $A_{B}$ was evaluated using eq. (B2) in Appendix B.

The heat transfer coeff: clent data are displayed in Fib. 4. As seen in F1g. 4, the heat transfer coefficlents are very large compared to the normal values of $0.01 \mathrm{cal} / \mathrm{cm} \mathrm{sec} c$ (or $50 \mathrm{BTU} /$ hr $\mathrm{rt}^{2} \mathrm{~F}$ ) expected from film bolling theory. The anditical predictions for the heat transfer coefficlent fall below the experimentel velues. However, the analytical trend seems to follow the experimental trend. Conbequently, if desired, an empiricel correction factor could be applied to the analytical expression to a ve agreement over a wide volume rarige.

Because the emissivity of mercury is smali. the heat is transierred to the drop primarliy by conduction scross the vepor gaf. Therefore, the vapor gap beneath the drop can be est1mated by the equation

$$
8=\frac{k}{h_{T}}
$$

The gap thickess is estimated to be on the order of ane ten-thousand of a centimetar. The hot plate surface was pollshed initially to a 5 micro-cm fin1sh.

There are at least two possible reasons why the analytical beat transfor coerficient underestimates the measured heat transfer coefficient. First, convection currents above the drop could enhance the diffusive manlsm from the upper surface of the drop. Second, because of the very small vapor gap thicksess and the large surface tension of mercury, some direct contact between mercury and the surface couid be occurring. It should be expected that analytical models, which assum an insulating vapor fllm and quiescent drops, will underestimate the masured heat transfer cosficient. Bradrield 15 indicated that liquid-solid contact cen occur even with lergo vepor gap thickness $(0.001 \mathrm{~cm})$ and low surface tenion Iutds. Harveyd(p. 42) Indicates that a large percent change in the droplet diamerer can occur du to direct contect. In addition, Marengon1

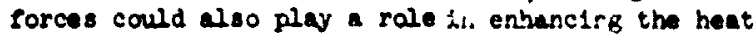
transfer coefficient. 


$$
\begin{aligned}
h_{T} A_{B} \Delta T=\frac{k A_{B} \Delta T}{\delta} & +h_{r a d} A_{r} \Delta T-h_{C O N V} A_{c}\left(T_{s}-T_{Q}\right) \\
& =-D_{v} \lambda w(8) A_{B}+\frac{\lambda D_{i B} M P_{B} A_{d}}{R T_{s} r_{0}}
\end{aligned}
$$

On the right-hand side of eq. (AI), the first term represents heat removed from the drop by evaporation from the lower surface, while the second term represents the latant heat requirements for the evaporation by diffusion from the upper surface. For the form of diffusive energy loss, the pertial pressure of the liquid in the vapor environment is assumed 3mall and an equivalent spher.cal shape has been assuned. Heat transfer to the drop occurs by conduction across the small vapor gap $\delta$, by radiation from the plate to the drop and by natural convection from the hot vapor and atmosphere surrounding the drop.

The momentum equation along with the appropriate boundary conditions was solved in Ref. 12 to give

$$
w(5)=\frac{2 \pi}{3} \frac{\left(Q_{L}-\rho_{V}\right) B \delta^{3}}{W^{L}}\left(\frac{V^{*}}{A_{B}^{* C}}\right)
$$

where $\mathrm{V}^{*}$ and $A^{*}$ are dimensionless volume and area of the botton of the drop respectively. They are defined by eq. (4) and (s) in the body of this report.

Equation (A2) is now comblned with the energy balance, eq. (AI), to determine the gap thickness of the vapor 8 ,

$$
8^{4}=0_{0}^{6}\left[1-\left(\mathrm{N}_{D C}-\frac{\mathrm{h}_{\mathrm{N}}}{\mathrm{h}_{0}}\right) \frac{8}{8_{0}}\right]
$$

where

$$
\begin{gathered}
N_{D C}=\frac{A_{d}}{A_{B}} \frac{A D_{A B} M P_{B}}{R T_{s} T_{0} \Delta T} \\
h_{\text {net }}=h_{\text {rad }} \frac{A_{I}}{A_{B}}-h_{\text {conv }} \frac{A_{C}\left(T-T_{B}\right)}{A_{B} \Delta T}
\end{gathered}
$$

and as shom in ser. 12 for pure fllm bollins, no radiation or diffunion

$$
\delta_{0}=\left[\frac{3 k \Delta \pi_{L} L}{2 \pi \lambda\left(q_{q}-\theta_{v} / D_{v} B\right.}\right]^{1 / 4}\left(\frac{A_{B}^{*}}{v^{*}}\right)^{1 / 4}
$$

and for the heat tranefor coofficiene

$$
h_{0}=\frac{k}{B_{0}}=1.21\left(\frac{k^{3}{ }^{*}\left(q_{L}-0_{v}{ }^{\prime} v^{B}\right.}{\Delta L}\right)^{1 / 4}\left(\frac{v^{*}}{A_{B}^{*}}\right)^{1 / 4}
$$

whore the latent heat of vaporization has been replaced by the modifled latent heat of raporization which accounts fur convect. on effects it. the vapor gap (see list of symbols).

The dimensionless group $N_{i r}$ is a measure of the 1mportance of diffusion from the upper surface of the drop to conduction beneath the drop.

Equation (A3) can be written as

$$
N_{D C}-\frac{h_{t \sqrt{E T}}}{h_{0}}=\frac{1-\left(\frac{\delta}{\delta_{0}}\right)^{4}}{\left(\frac{\delta}{\delta_{0}}\right)}
$$

The exact solution of eq. (AB) is presenten in

F1g. 6 . For smeill values of $\mathrm{N}_{D C}$

$$
w_{D C}-\frac{n_{N E}}{n_{0}} \leq 2
$$

The solution for $8 / 8$ o can be written as

$$
\frac{\varepsilon}{\varepsilon_{0}} \equiv 1-\frac{1}{4}\left(N_{D C}-\frac{n_{N E T}}{n_{0}}\right)
$$

For large values of $N_{D C}$

$$
\begin{aligned}
& N_{D C}-\frac{h_{\text {iVI }}}{h_{0}}>2 \\
& \frac{\delta}{\delta_{0}} \approx \frac{1}{N_{D C}-\frac{h_{N E T}}{h_{0}}}
\end{aligned}
$$

The solution for the heat transfer coefricient and vaporization times presented in Ref. 10 was based on eq. (AlO), that 1s, diffueion is relatively alm compared to heat conduction acrose the vapor gap. For mercury drope in either air or an inert atmosphere, eq. (AlO) is not vaild because $N_{D C}$ is large (In the range of 5 to 10 for the mercury deta). The balance of this appendix is coricerned with the derfvation of the heat transfer coefficient using eq. (Ali) where diffusion dominates.

The total heat transfer coefficient can now te found by subtituting from eq. (A12) linto the lefthanci side of eq. (AI).

$$
n_{T}=\frac{\lambda I_{A B} M H_{s} A_{d}}{R T_{s} \Delta T T_{0} A_{E}}
$$

Th1s form of the heat transfer confficient could be obtainad directiy from eq. (AI) by simply negiecting the erfect of vapor flow $\left(-a_{A} \wedge A_{B}\right)$ beneath the drop. The analyuls has indicated that this is a permissible assumption $18 \mathrm{~N}_{D C}-h_{\mathrm{KET}} / \mathrm{h}_{0}$ is greater than 2 .

Non-dimensionalizing eq. (AL3) is the tanner suggested by eq. (7) in the body of the report gives

\section{ORIGLNAT PAOT \\ or poor consr.}




$$
h_{T}^{*}=\frac{\lambda D_{A B} M P_{s}}{N_{s} \Delta T r_{0}} \frac{A_{d}}{A_{B}}\left(\frac{k^{3} \lambda^{*}\left(q-\rho_{V}\right) \rho_{V} B}{\Delta L}\right)^{-1 / 4}
$$

The expression for $h_{T}$ depends on volume through the terms $F_{0}, A_{d}$, and $A_{B}$. The voluse dependence of $r_{0}, A_{d}$, and $A_{B}$ are given respectively by eqs. (B4), and (B6). Subat1tuting these values into eq. (Ali) gives

$$
h_{T}^{*}=\frac{N^{*}}{v^{* 0.964}}
$$

where

$$
N^{*}=\frac{30.7 \lambda D_{A B} M P_{B}}{\Delta T T_{B}}\left(\frac{k^{3} \lambda^{*}\left(p_{L}-\rho_{V}\right) Q_{Q B}}{\Delta T H I}\right)^{-1 / 4}
$$

\section{Appendix B}

\section{Area of Drop}

The theory of Ref. 10 besed the area of heat transfer on the maximum radius of the drop. However. - or dimensionless drop volumes less than 5, thet is

$$
v^{*}=\frac{v}{\left[\frac{\sigma g_{c}}{\left(q_{L}-\rho_{v}\right)_{g}}\right]^{3 / 2}}<5
$$

the contact area is considerably smaller than the area subtended by $r_{\text {max }}$. This is shown pictorially In Fig. 7. The curves were generated from the dats of Ref. 14. The curves can be fitted by the fallowIng equations:

$$
\begin{array}{ll}
r_{c}^{*}=0.282 v^{* 0.55} \quad v^{*}<5 \\
r_{c}^{*}=\frac{1}{3} v^{0.525} \quad v^{*} \geq 5 \\
r_{0}^{*}=\left(\frac{3 v^{*}}{4 \pi}\right)^{1 / 3} \quad v^{*}<5 \\
r_{0}^{*}=0.4 v^{* 0.465} \quad v^{*} \geq 5
\end{array}
$$

by

The ratio of difrusion to contact area io given

$$
\begin{aligned}
& \frac{A_{d}}{\Lambda_{B}}=\frac{4 \pi r_{0}^{* 2}}{\pi r_{c}^{*}}=\frac{4\left(\frac{3 v^{*}}{4}\right)^{2 / 3}}{0.25 v^{* 1.3}} \quad v^{*} \leq 5 \\
& \frac{A_{d}}{\Lambda_{B}}=\frac{\pi r_{0}^{* 2}}{\pi r_{c}^{* 2}}=2.25 / v^{* 0.12} \quad v^{*}>5
\end{aligned}
$$

As an aralyticel aimplification, the equation for the drop's surfecr area in eq. (BG) is assumed to be represented by a complete spare. That 1s, the area due to the Hattoning of the spherc at the plate is neglected. For $\because$ greacer than 5 . the drop is assumed to be represented by a flat cyllnder, such that only the upper area contributer to diffusive evaporation.

\section{References}

1. Baume1ster, K. J., Hamill, T. H., and Schoessow, G. J., Proceedings of the Ihira Internationel Heat Transfer Conference, Vol. 4, Americen Institute of Chemical Engineers, New York, 1966, pp. 59-65.

2. Gotifried, B. S., Lee, C. I., and Bell, K. I., Int. J. Heat Mass Transfer, 9, L167-2188, 1966.

3. Wachters, L. I. T., boctoral thests, Fechrical university of Lelft, ictherlasds, $19 . \mathrm{.}$.

4. Harvey, D. M., Doctoral Thesis, MuMacter University, Hamilton, Ontario, Carada, 196.7.

5. Bell, K. 4., Them. Eng. Prog. Symp. Ser., 63. $73-82,1967$.

6. Temple-Pedian1, R. W., Proc. Inst. Mech. Ent.. 184 (Pt. 1), 677-69n, $1965-1970$.

7. Poppendiek, H. F., et al, SAN-409-29, AEC Contract AT (04-3)-409, Jan, 1966.

8. Poppendiek, H. F., NASA CR-72759, Aucust 1970.

9. Schoeseow, G. T., and Baumeister, K. A. AIChE Symp. Sertes 118, Vol. $68,1972, p e .156-161$.

10. Beumeister, K. J., and Sc' Jessow, G. I., ALChE Sym. Series 13i, Vol. ؟, 1973, p8. 10-17.

21. "Occupational Exposure to Inorganle Mercury," U.S. Dept of Health Education a.. Wellare, 1973.

12. Reid, R. C., and Sharwood, T. K., "The propert1rif of Gases and LIquids," MeGraw-H!1], New York, 195 P

13. Beumetcier. K. S., and Hamill, T. L., MASt T:: $-3133,106.5$.

14. Baumoteter, K, J., and Hamill, T, D., IASA TN $D-4779,1968$.

15. Bradrield, W. S.. Ind. Ens. Chem, Fundamentals, 5, 200-204, 1960. 
0
$\vec{c}$
0
1
1
$\omega$

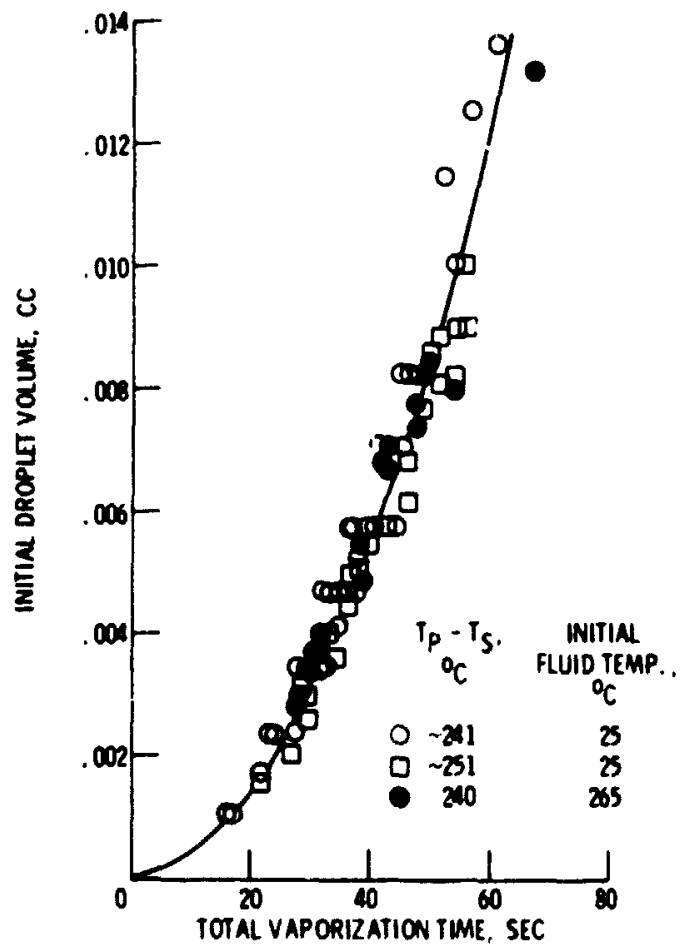

Figure 1. - Total vaporization time of merciry.

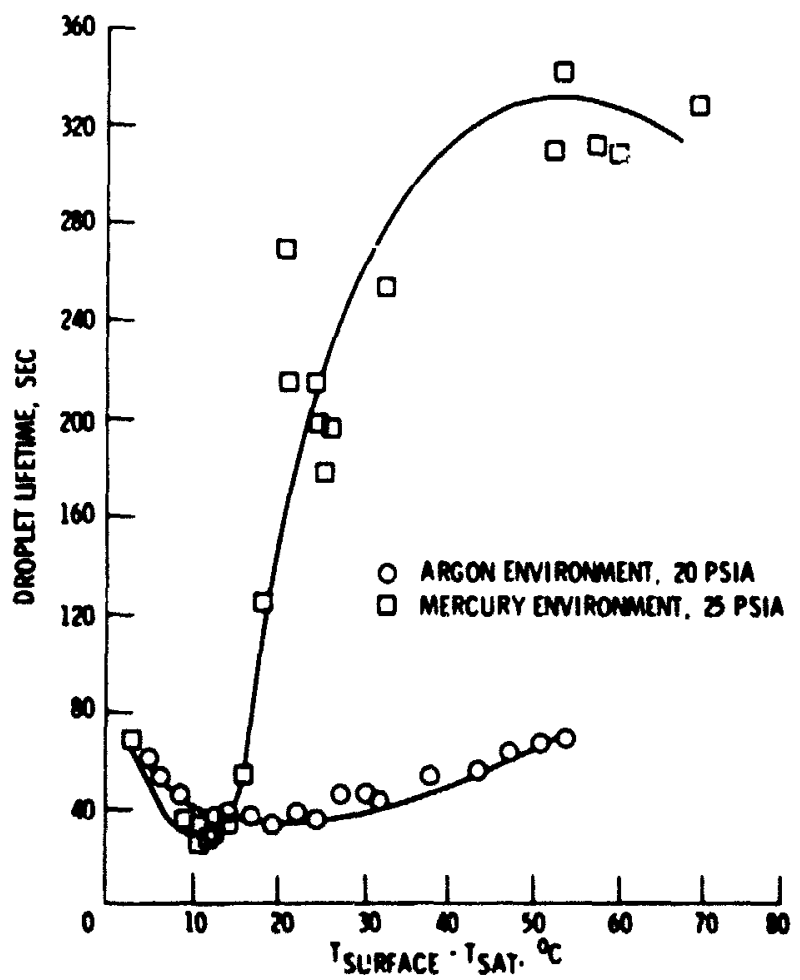

Flaure 2 - The llidtanes of mercury droplets veporizing on a bentalum surtace in an argon and mercury cowirenement (retereme 8. 


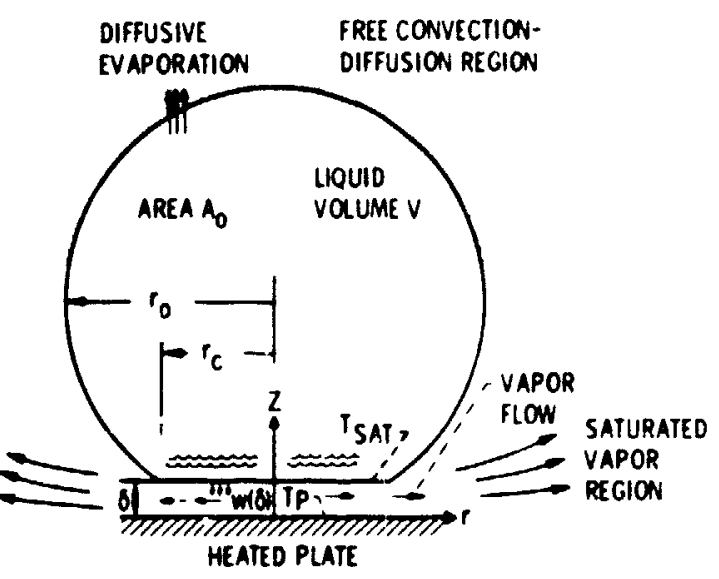

Figure 3. - Schematic model for eveporation of fit botion sphere.

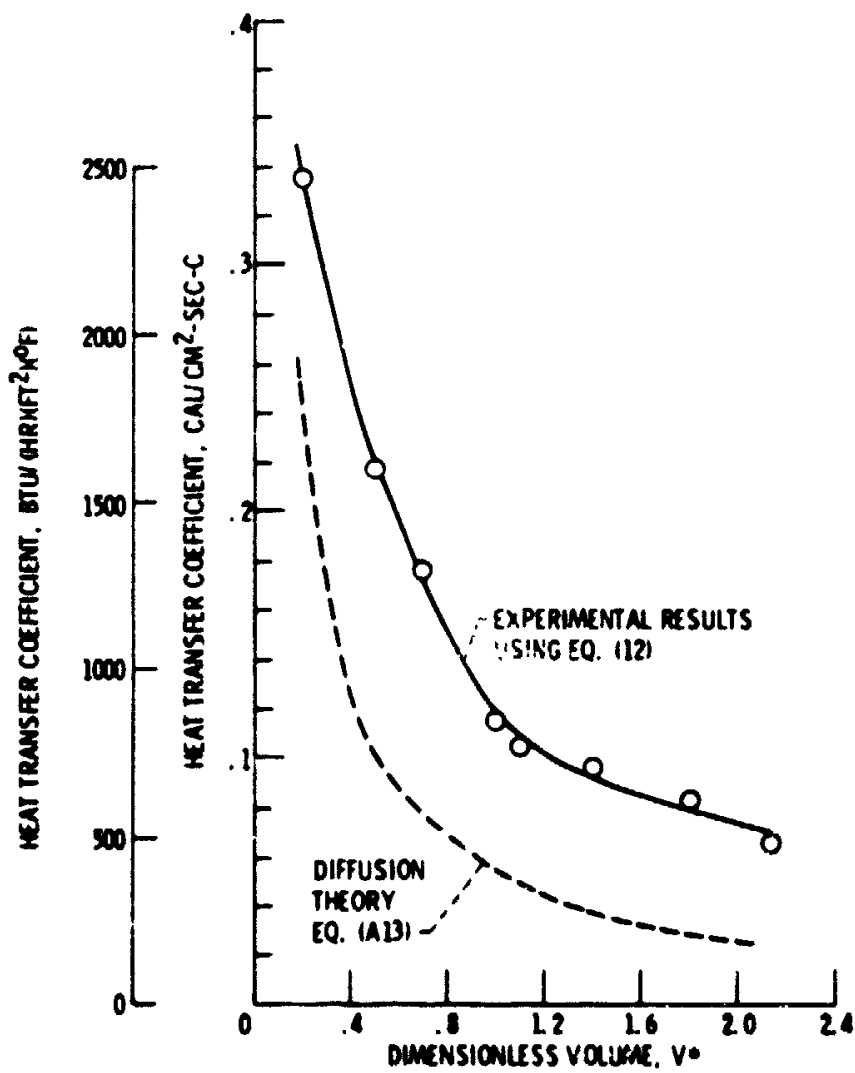

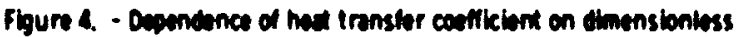
volume bo mercuny oropits. 


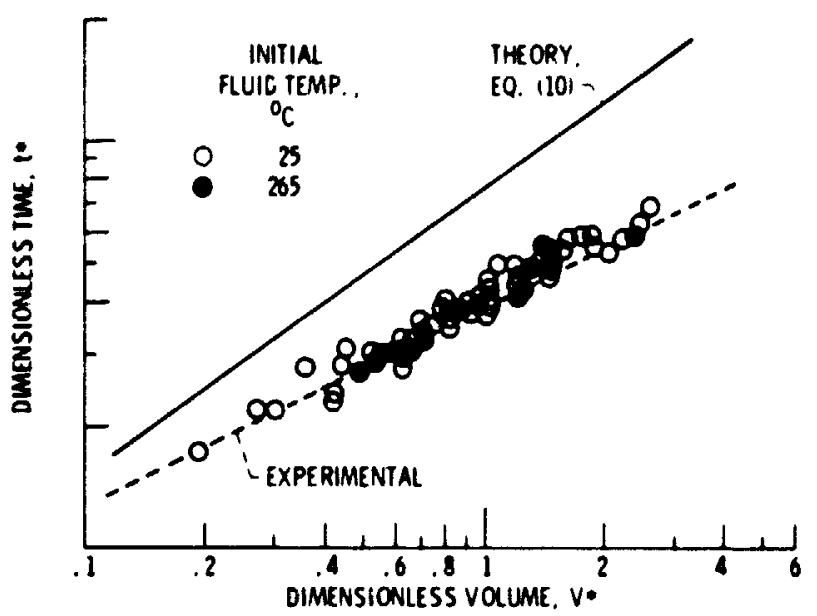

Figure 5. - Iotal vaporization lime of mercuny droplats.

0
$m$
$\infty$
1

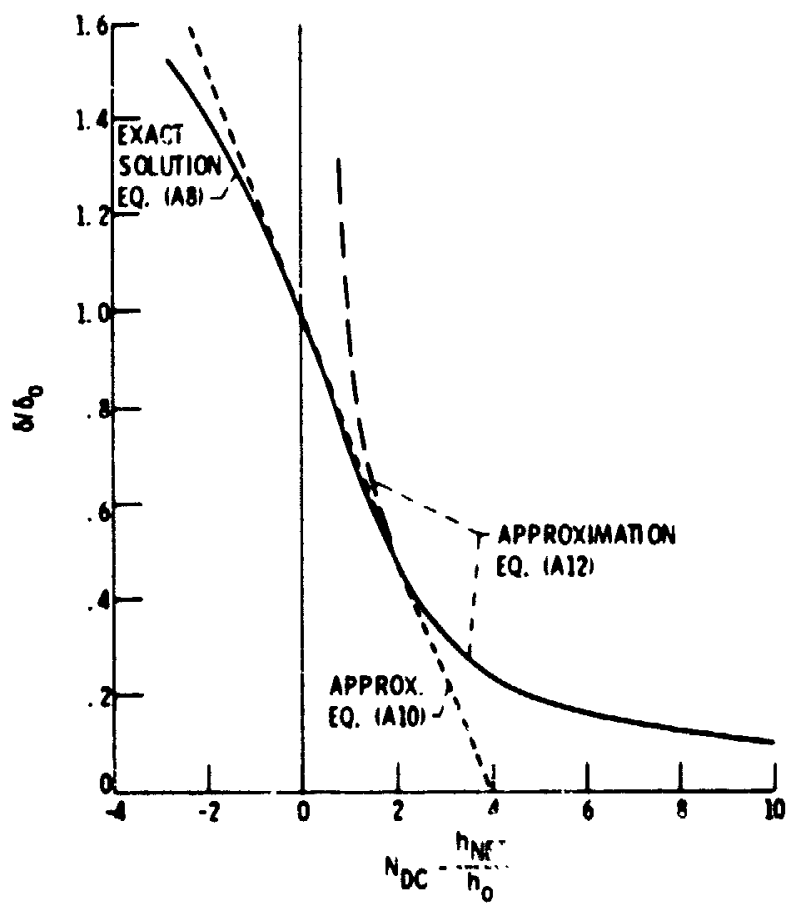

Figure 6. - Exac and pproximate rolationships of $8 / b_{0}$ to the quenity $\left.w_{D C} \cdot h_{N} T^{\prime h_{0}}\right)$. 

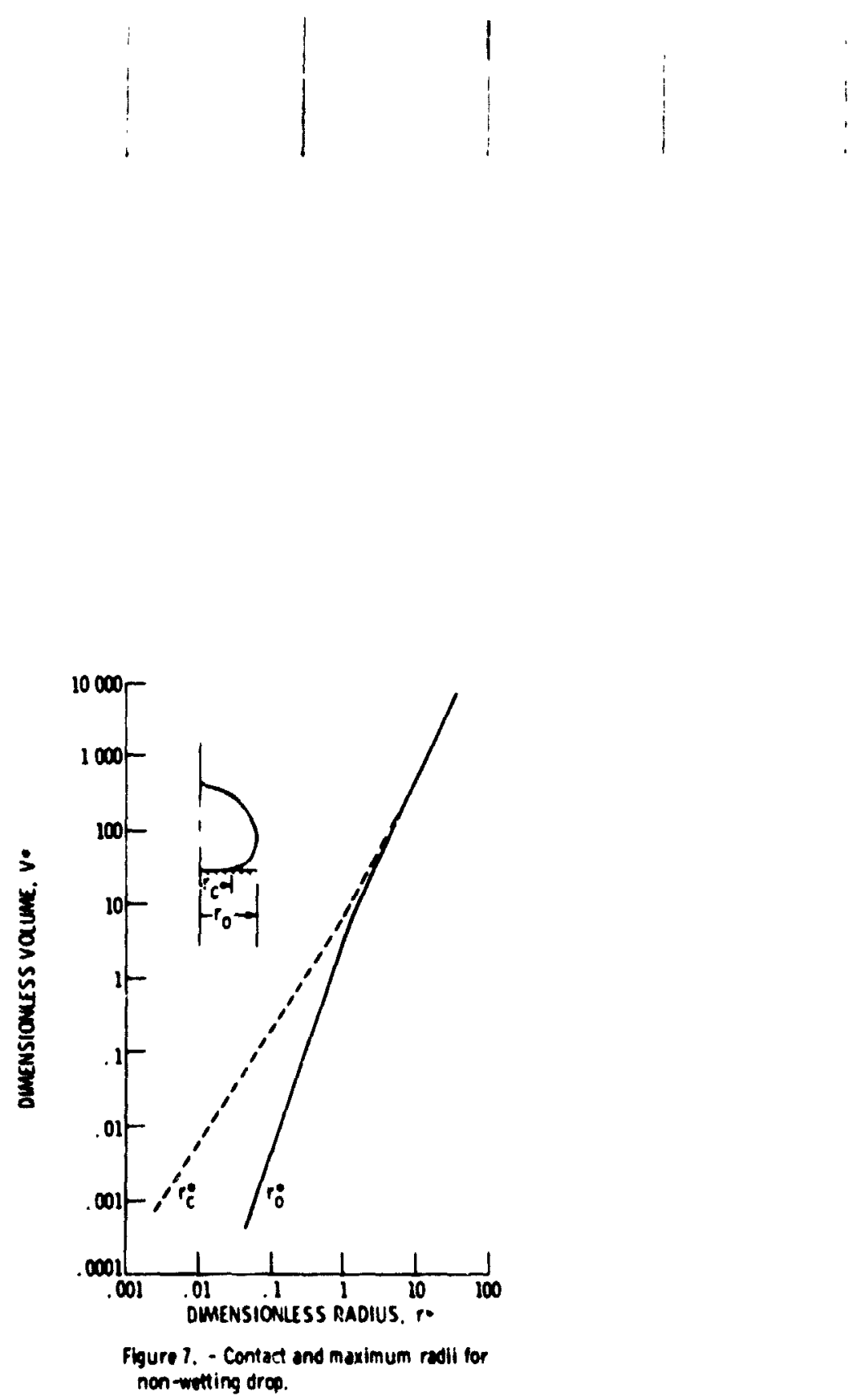

MRAL PLC: 18

TOOR COALITY

MASA.Lem Is 